\title{
ANALYSIS OF ROUGHNESS PARAMETERS OF LATERAL BACK SURFACES OF MODEL HOB MILLING TOOLS DURING CYLINDRICAL GEAR CUTTING
}

Original scientific paper

UDC: $621.9 .011: 621.89$

https://doi.org/10.18485/aeletters.2018.3.2.3

\author{
Ivan Sovilj-Nikić ${ }^{1}$, Sandra Sovilj-Nikić ${ }^{2}$, Bogdan Sovilj ${ }^{1}$, Ivan Samardžić ${ }^{3}$, Dražan Kozak ${ }^{3}$, Vladimir \\ Blanuša ${ }^{4}$
}

${ }^{1}$ Faculty of Technical Sciences, University of Novi Sad, Trg Dositeja Obradovića 6, 21000 Novi Sad, Serbia

${ }^{2}$ Iritel a.d. Beograd, Batajnički put 23, 11080 Beograd, Serbia

${ }^{3}$ Faculty of Mechanical Engineering, Ivane Brlić Mažuranić 2, 35000, Slavonski Brod, Croatia

${ }^{4}$ High Technical School of Professional Studies, Školska 1, 21000 Novi Sad, Serbia

\begin{abstract}
:
The problem of generating is analyzed in science and practice in various ways by identifying it once as an element of the machine, and the second time as a part of production, that is, a final product. The nature of the materials of the machine elements, the loads in the contact zone, the relative velocities, the topography of the contact surfaces, and the temperature in the contact zone influence on the tribological characteristics of the elements, and hence on the characteristics of the tribo-mechanical systems. The surfaces of the tribo-mechanical elements of the machines through which mutual contact is realized are essentially thin layers of materials whose composition and properties differ significantly from the properties of the basic mass element material. There are a significant number of tribo-mechanical systems in the energy sector. Gear cutting is the most important operation in the production of gears. The quality of the gear cutting is one of the conditions for achieving the required quality of the work-piece. The gear is an element of a large number of tribo-mechanical systems. The geometrical parameters of the hob milling, the accuracy of the profiling and the accuracy of manufacture significantly affect the productivity and machining costs. In this paper, the topography and roughness parameters of lateral back surfaces of the model hob milling tools are analyzed before and after cylindrical gear cutting.
\end{abstract}

\section{ARTICLE HISTORY}

Received: 15.01.2018.

Accepted: 02.02.2018.

Available: 30.06.2018.

\section{KEYWORDS}

tribo-mechanical systems, cylindrical gear, gear and tool materials, tribological characteristics, topography, roughness, model hob milling tools

\section{INTRODUCTION}

The contemporary characteristics of the society and the desire for continuous improvement of the quality of life require continuous improvement of the quality of production. The product is the most characteristic parameter of the technical development of a country. Analyzing the centurylong coupling and mutual relations between man and the industrial product, at each stage of their life cycle, it can be concluded that the industrial product is material creation which is consciously developed and realized in industrial conditions of production. By directing the process of development of production to the development of various systems, it is especially important to find ways to improve the quality of products.

In tribological processes, the very small mass of the tool material and the large mass of the material of the work-piece are involved in the gear cutting. Scheme of tribological system and four different types of boundary between the base and coating are given in Fig.1 [1]. 


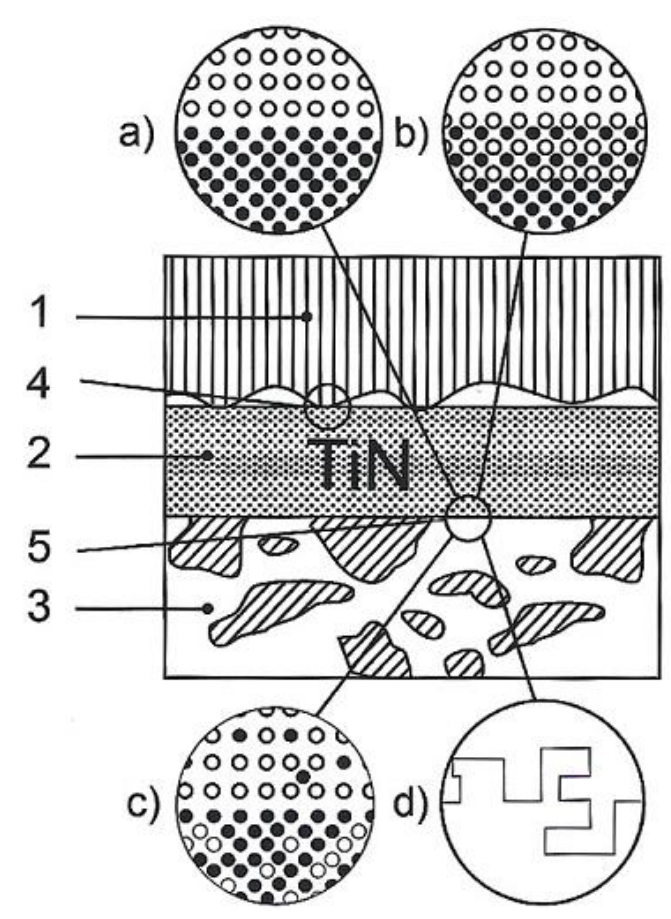

Fig. 1. Scheme of tribological system: 1-work-piece, 2hard coating, 3-base, 4-tribological contact (lubricant), 5-adhesive joint between the coating and base: a (keen boundary, b) connected boundary, c) diffusion boundary, d) mechanical boundary

The consequences of the development of tribological processes in the zones of contact are the friction and wear of the cutting elements of hob milling tools. In the Fig.2 [2] examples of tribomechanical systems are given, and with the number one the critical element of each tribo-mechanical system is marked, that is, the element which is worn at the most in the process of achieving contact.

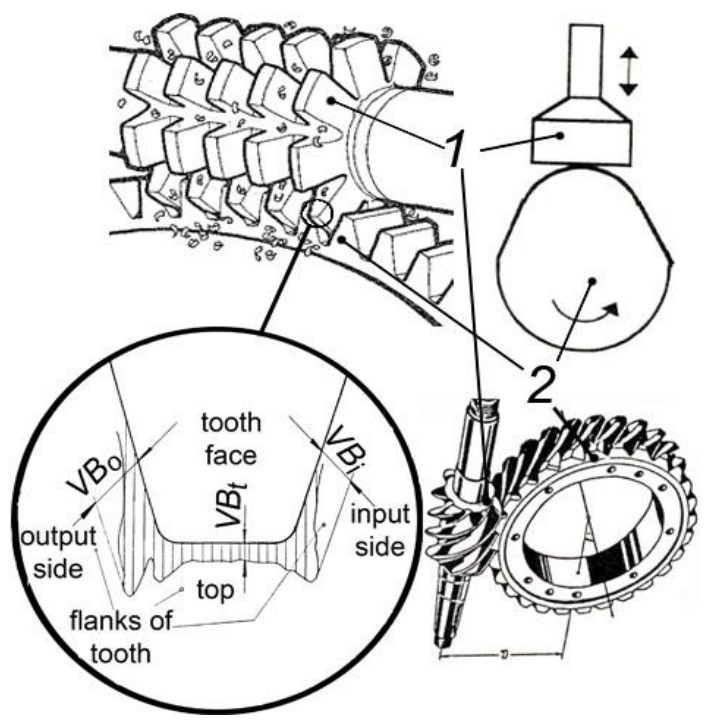

Fig. 2. Example of tribo-mechanical systems with basic elements 1 and 2 and details with wear parameters of hob milling tool
The contact surface of the tribo elements after final machining is never absolutely smooth. Numerous unevennesses resulting from previous and final operations can have different geometric parameters and cause greater or minor irregularities in triboelements.

It is indisputable that the change in system structure, energy losses and material losses are very complex processes and depend on a large number of factors.

Numerous studies have shown that the quality of the contact surface significantly affects the wear resistance. Reducing the roughness increases the wear resistance.

In this paper a part of the results of the research of tribological processes in gear cutting with uncoated and coated model hob milling tools is presented.

\section{GEAR CUTTING AND THE TOPOGRAPHY OF THE SURFACE}

The occurrence of the power transmitter and movement dates back to ancient times. In China, Mesopotamia and Egypt, parts and assemblies of irrigation devices with toothed portable elements have been found, which according to the kinematic principle are still used today. In addition to agriculture, such devices have been developed for war and civil engineering purposes Fig.3 [3].

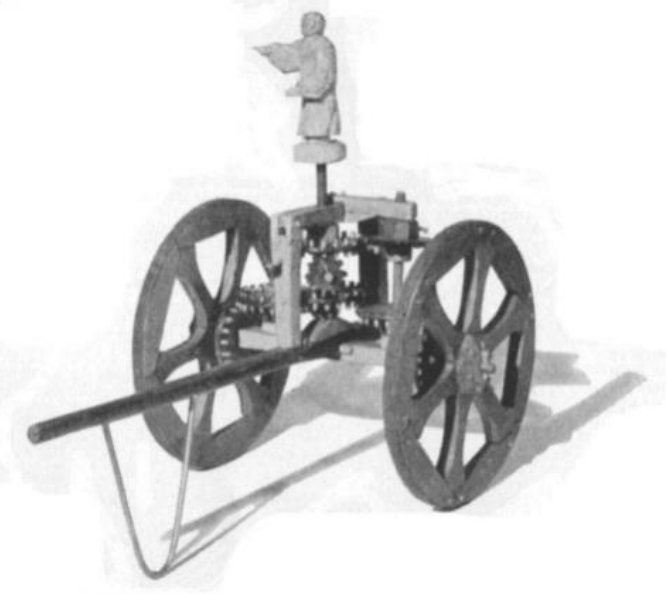

Fig. 3. South pointing chariot

Gear cutting can be done by various methods and procedures. Thanks to the high productivity of the process, the hob milling has the widest application in the machining of serration of spur wheels.

Integral hob milling tools are tools used in machining of gear serration by means of relative rolling method (Fig.4). 


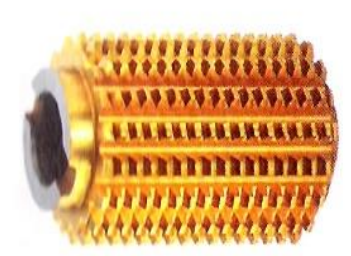

a)

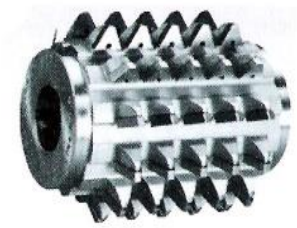

b)

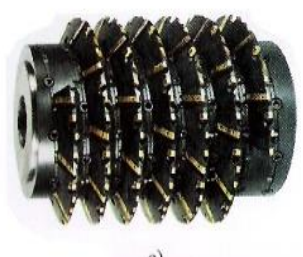

c)

Fig. 4. Hob milling tools (a. Integral, b. assembly, c.montage)

In defining the tool life of hob milling tool, it is necessary to perform long-term experimental tests which require considerable resources and efforts, and it is difficult to implement them in the real production process. In order to simplify this experimental research, there is a need for quick and cheaper testing procedures that will provide reliable information on the examined machining process. For the process of hob milling of gear serration, there is a possibility that instead of the integral hob milling tool, model single-tooth hob milling tool can be used in research (Fig.5 [4]).

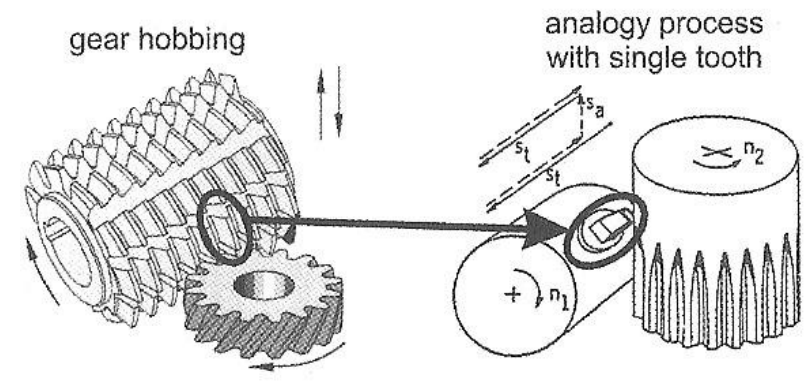

Fig.5. Gear hobbing represented by a single tooth flycutting analogous process

For the process of gear cutting, a method has been developed, device for accepting a cutting element (teeth) for model testing in laboratory conditions instead of an integral hob milling tool has been designed and manufactured (Fig.6 [2]).

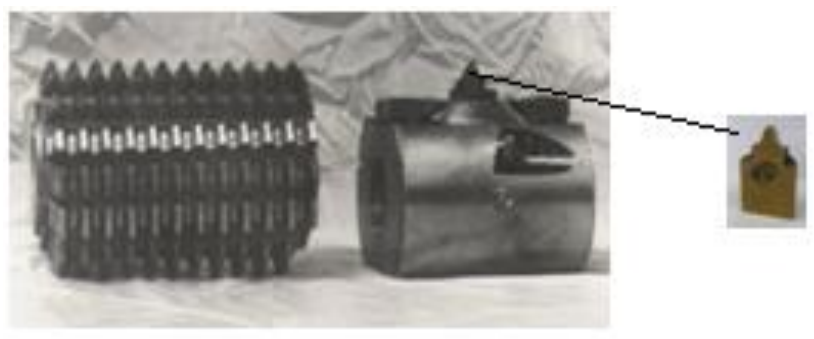

Fig. 6. Integral and model tools
Significantly the largest percentage of all breakdowns and slowdowns in production is initiated through the surface of the elements of the tribo-mechanical system through mechanisms such as fatigue fracture, fracture due to stress corrosion, contact wear due to friction, erosion, etc. It is clear that is important to know the properties of surfaces and zones near the surface of the elements. The answer to these problems can be given by tribology [5-12].

The interdisciplinary character of tribology and a wide array of possible aspects of the study have conditioned that in the process of tribologically correct design and construction, it has to be equipped with a large number of precisely defined tribological information.

Due to the complexity of the tribological processes and the large number of influencing factors, it is necessary to possess information from various disciplines of this broad scientific field. In that sense, the development of triboinformatics encourages as the necessity of systematizing an increasing number of tribological information and the need for a more efficient exchange between scientific institutions and other potential users of tribological knowledge [13].

Insufficient state of scientific knowledge in the field of hob milling requires further development and research of this kind of machining. Lack of information is increased by applying a variety of tools and materials of hob milling in the machining of gears teeth which are made of various materials.

Economy of gear cutting depends primarily on the character of teeth wear of hob milling tool. Numerous factors and their alternating effects make the research of wear process of hob milling tool very difficult. Influential parameters on wear process of hob milling tool is shown in Fig.7 [2].

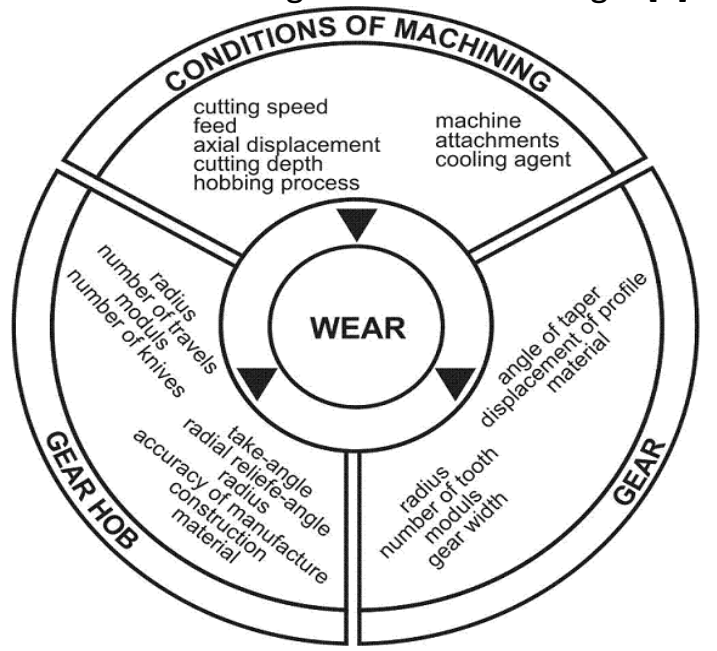

Fig. 7. Influential parameters on wear process of hob milling tool 
Detailed analysis of the most influential factors and parameters can serve as a basis for understanding the ways of increasing economy of gear cutting by hob milling. Wear is one of the ending negative phenomena in the machining processes. It is believed that the relatively high pressures and high temperatures on contact surfaces of coupled pairs, and the high relative velocity of the coupled pairs are the basic conditions for the occurrence and intensive development of tool wear process. Wear of cutting elements of hob milling tools takes place continuously in all moments of contact, and also in all technological conditions and machining regimes $[5,6,14]$.

The design quality is one of the essential factors of product quality and one of the most important conditions in product development. The gear cutting tool is a product of a certain branch of production. During production, tribological processes occur. It is indisputable that tribological processes are very complex processes and also depend on a large number of factors. Because of this, there are many possibilities that the designer, or constructor, can develop a tribologically correct construction in the design process. As in a wider sense, at this time the construction is organized and regulated in the correct tribological behavior, the available possibilities are divided into three groups of regulators: structural, technological and exploitation (Fig.8) [6, 13].

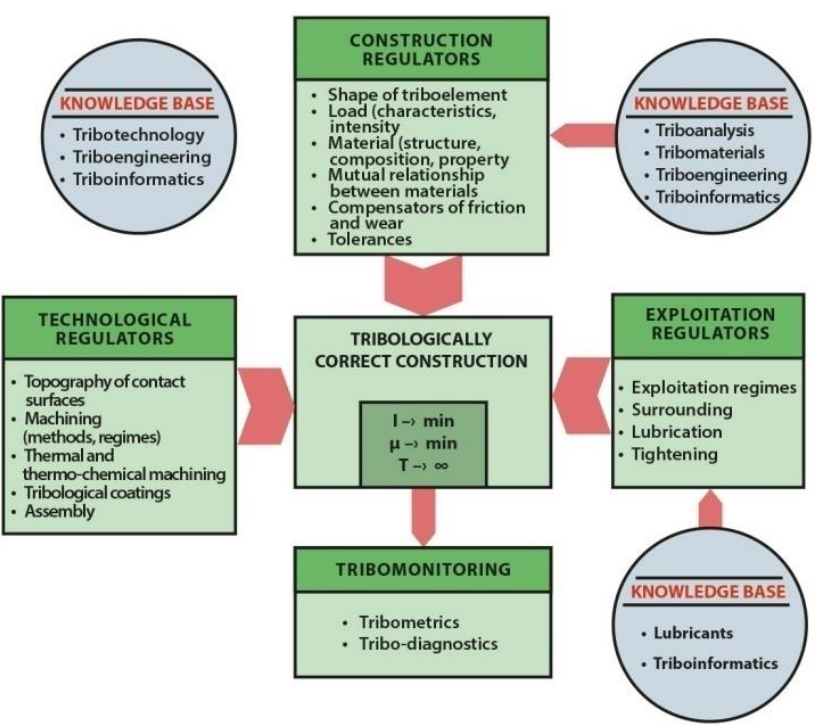

Fig. 8. Regulators of tribologically correct construction

Technologists study technical drawings and they try to produce elements by defined dimensions within the limits of tolerance. Characteristic parameters formed during the technological process define macrogeometry and microgeometry of contact surfaces. The connection between topography of contact surfaces and the development of tribological processes is very complex. The change of topography in the development of tribological processes can be shown by the model as in the Fig.9 [14].

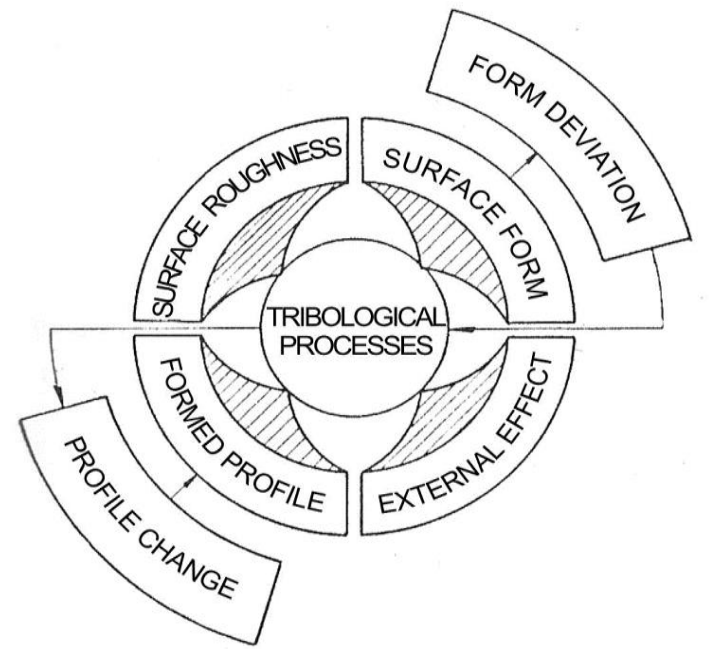

Fig. 9. Change of topography during development of tribological processes

For the correct analysis of tribological processes, but also tribologically correct construction, the roughness of the contact surfaces is especially significant. Macrogeometry can be repaired during the technological process itself by working properly on the system; machine-fittings-tool-work-piece. Roughness has a stochastic element and it is a consequence of random processes, it cannot be avoided, but it can be managed to a large extent in the technological process of machining [15].

For analysis of the roughness of the machined surface of the elements, there are more than 30 parameters that are less and those that are more represented. The basic parameters of roughness are defined according to national and international standards. The first three parameters $R_{a}, R_{\max }$ and $R_{z}$ represent a small group of the three most common parameters, while $R_{t}, R_{q}$ and $R_{p}$ are the parameters that are also used, but considerably less than the three previously mentioned roughness parameters.

Roughness significantly affects the actual surface of the contact, that is, the surface on which the contact of the micronuclei that forms the topography is realized. The actual surface of the contact depends on the micro and macro geometric characteristics of the surfaces in contact, from the corrugation, form errors, physical mechanical properties of the surface layer, from the load, etc. With the load parameter, the actual surface of the contact increases, and the growth is conditioned by the emergence of new contact points [16]. 
In constructing of tribo-mechanical elements in addition to the types of materials, it is necessary to define the shape of the element, its dimensions, tolerances, thermo-chemical treatment and the quality of surface machining of each surface.

The geometric shape of each surface is commonly referred to as surface texture. Conventional when the surface texture is measured quantitatively, only roughness is measured and the waviness and shape elements are mechanically, electrically or digitally filtered from the obtained data.

The quality of machining affects the exploitative characteristics of the elements and their price, which is why it is necessary to pay great attention to the choice of machining quality. The constructor should not prescribe very precise machining of the surfaces of the elements so that they would be smoother because it is expensive and the production would be very uneconomic. Therefore, it is necessary to find the optimum functionality and economy. The surface has to as rough as possible to make the machining of this surface cheaper, but it has to be obligatory to fulfill the functionality requirement [17].

\section{MATERIALS AND METHODS}

According to research plan in the project entitled by Modeling and optimization of hob milling the analysis of the topography of gear cutting tools and machined teeth of spur wheels was planned. Within this paper, only parts of the results related to the topography for gear cutting are given. Based on the experiment plan, the research was carried out on uncoated and coated model hob milling tools with modules $\mathrm{m}=3 \mathrm{~mm}$ and $\mathrm{m}=5 \mathrm{~mm}$.

At the beginning of experimental topography research 392 model hob milling tools were identified based on certain characteristics. The roughness parameters were first measured on unworn tools, and then on the same tools after reaching the wear criterion. Roughness parameters are measured on model tools, which were already worn before this research. From the group of 392 tools 104 model hob milling tools have been allocated with module $\mathrm{m}=3 \mathrm{~mm}$ (Table 1 ) and $\mathrm{m}=$ $5 \mathrm{~mm}$ (Table 2). In each subtype, there are 13 model hob milling tools, and in Fig.10 a subtype of uncoated worn-out model hob milling tools with the module $\mathrm{m}=5 \mathrm{~mm}$ is given.

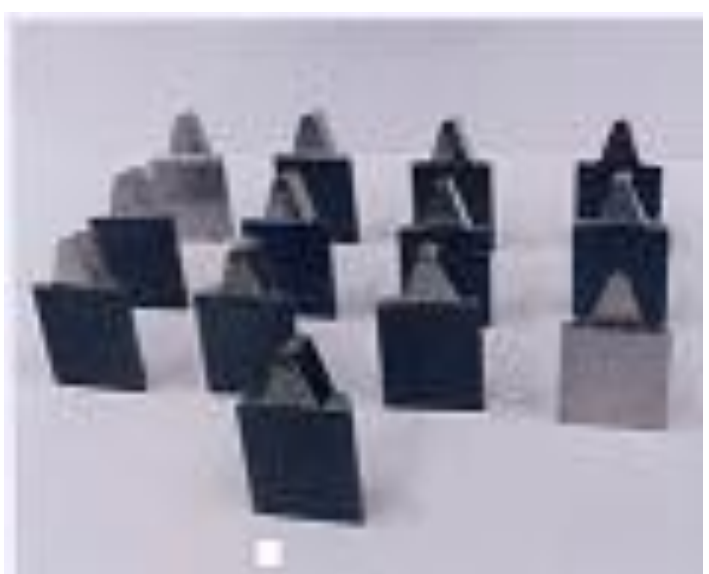

Fig. 10. Uncoated worn-out model hob milling tools with the module $m=5$

Table 1. Subtypes of model hob milling tools $m=3 \mathrm{~mm}$

\begin{tabular}{|l|c|c|c|c|}
\hline $\begin{array}{l}\text { MODULE } \\
\mathbf{m}=\mathbf{3} \mathbf{~ m m}\end{array}$ & $\mathbf{1}$ & $\mathbf{2}$ & $\mathbf{3}$ & $\mathbf{4}$ \\
\hline UNCOATED & $*$ & $*$ & & \\
\hline COATED & & & $*$ & $*$ \\
\hline UNWORN & $*$ & & $*$ & \\
\hline WORN-OUT & & $*$ & & $*$ \\
\hline
\end{tabular}

Table 2. Subtypes of model hob milling tools $m=5 \mathrm{~mm}$

\begin{tabular}{|l|c|c|c|c|}
\hline $\begin{array}{l}\text { MODULE } \\
\mathbf{m}=\mathbf{5} \mathbf{~ m m}\end{array}$ & $\mathbf{1}$ & $\mathbf{2}$ & $\mathbf{3}$ & $\mathbf{4}$ \\
\hline UNCOATED & $*$ & $*$ & & \\
\hline COATED & & & $*$ & $*$ \\
\hline UNWORN & $*$ & & $*$ & \\
\hline WORN-OUT & & $*$ & & $*$ \\
\hline
\end{tabular}

In these experiments, a model hob milling tools made of HS 6-5-25 was used and a number of tools were coated with TiN. To measure roughness parameters, a MahrSurf PS1 device was connected to a computer, so the measurement results were obtained in electronic form (Fig.11).

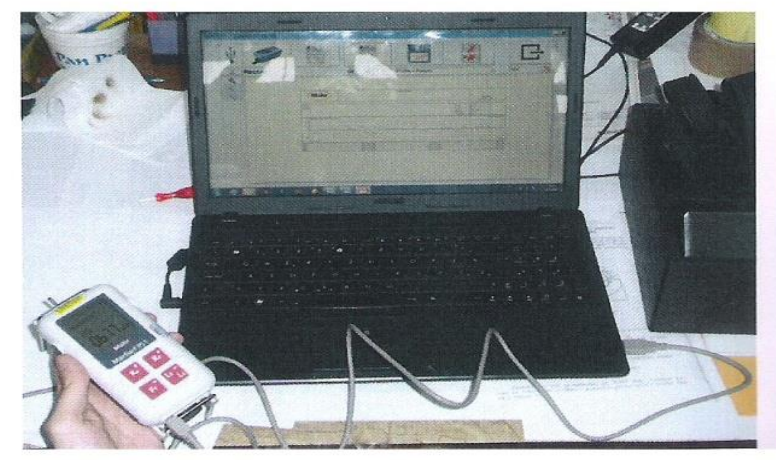

Fig. 11. MahrSurf device connected to computer

The surfaces of model hob milling tools and measuring directions are shown in Fig.12. 


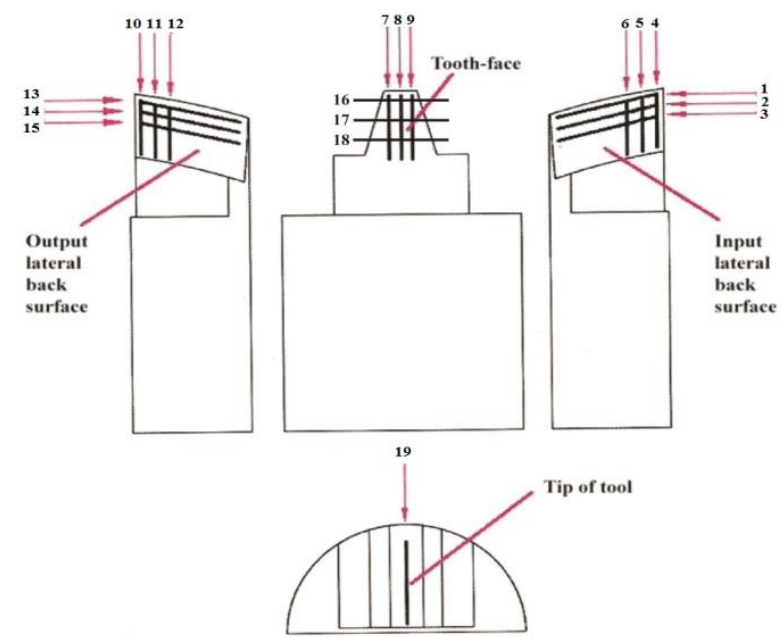

Fig. 12. Tool surfaces and directions of measuring

\section{RESULTS AND DISCUSSION}

In this paper, two types of experimental research were performed. The first experimental study presents a comparative analysis of the roughness parameters of the input and output lateral back surfaces of the model hob milling tools that were measured in the unworn and worn-out state. The second experimental study contains the analysis of the roughness parameters of the input and output side lateral back surfaces of four subgroups of thirteen model hob milling tools.

The results of the research are shown in diagrams and a part of the results is given in this paper in Fig.13-26.

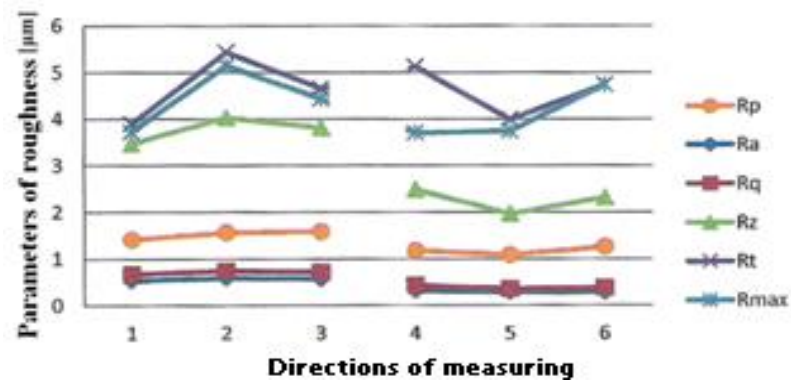

Fig. 13. Diagram of roughness parameters of the input lateral back surface of uncoated tool 7 unworn module $\mathrm{m}=3 \mathrm{~mm}$

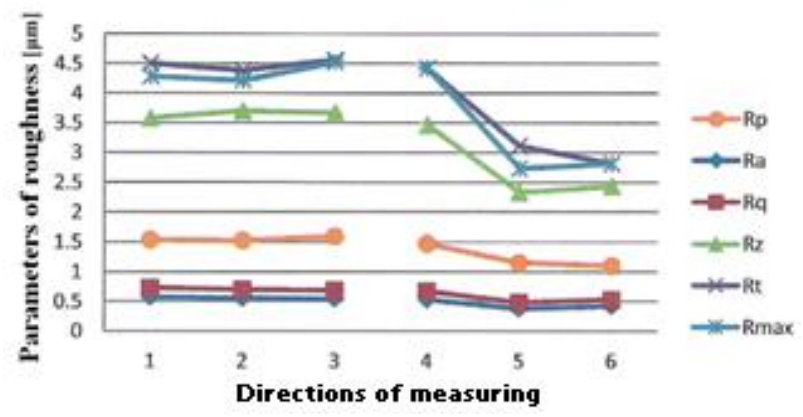

Fig. 14. Diagram of roughness parameters of the input lateral back surface of uncoated tool 7 worn-out module $\mathrm{m}=3 \mathrm{~mm}$

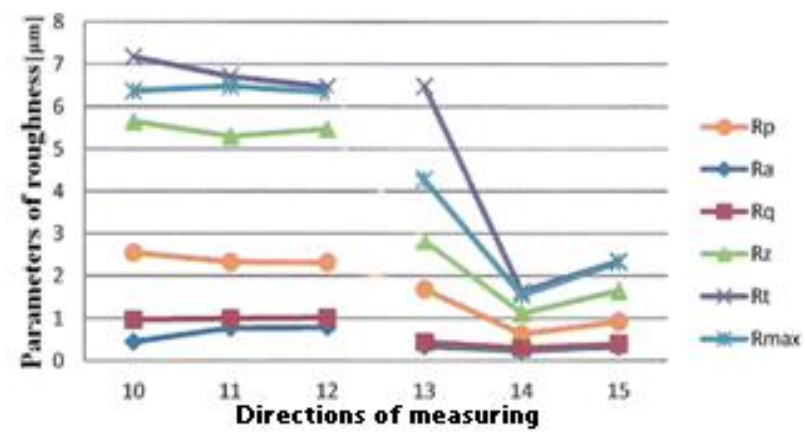

Fig. 15. Diagram of roughness parameters of the output lateral back surface of uncoated tool 7 unworn module $\mathrm{m}=3 \mathrm{~mm}$

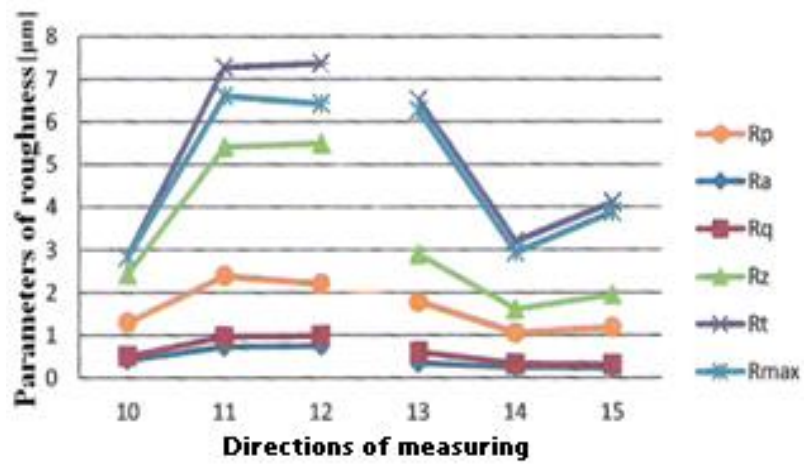

Fig. 16. Diagram of roughness parameters of the output lateral back surface of uncoated tool 7 worn-out module $\mathrm{m}=3 \mathrm{~mm}$

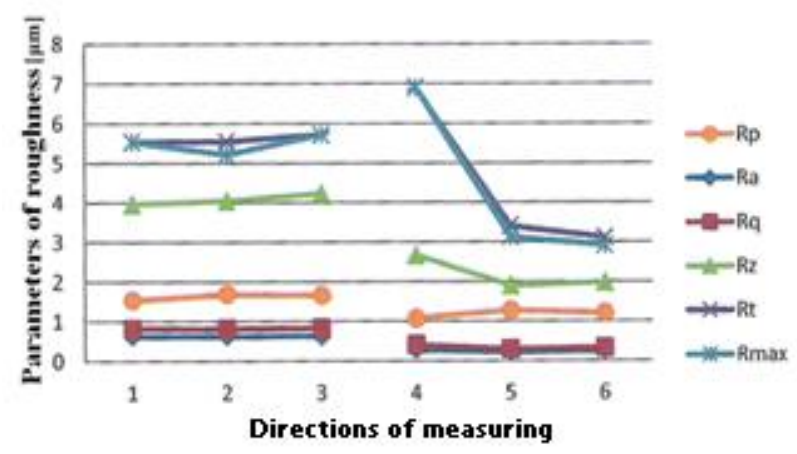

Fig. 17. Diagram of roughness parameters of the input lateral back surface of coated tool 13 unworn module $\mathrm{m}=3 \mathrm{~mm}$

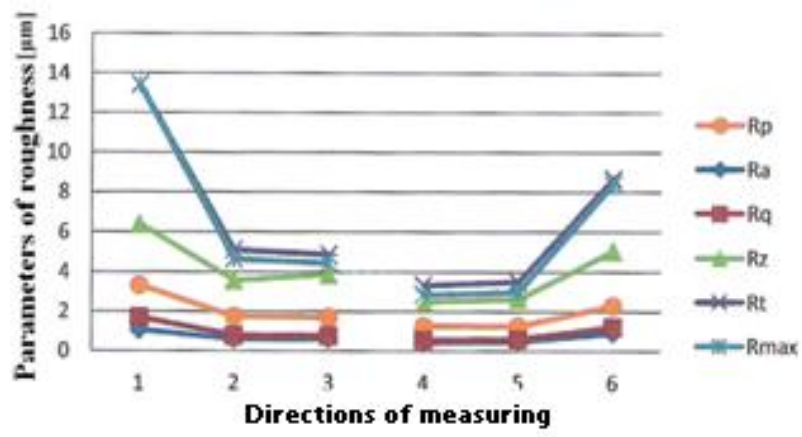

Fig. 18. Diagram of roughness parameters of the input lateral back surface of coated tool 13 worn-out module $\mathrm{m}=3 \mathrm{~mm}$ 


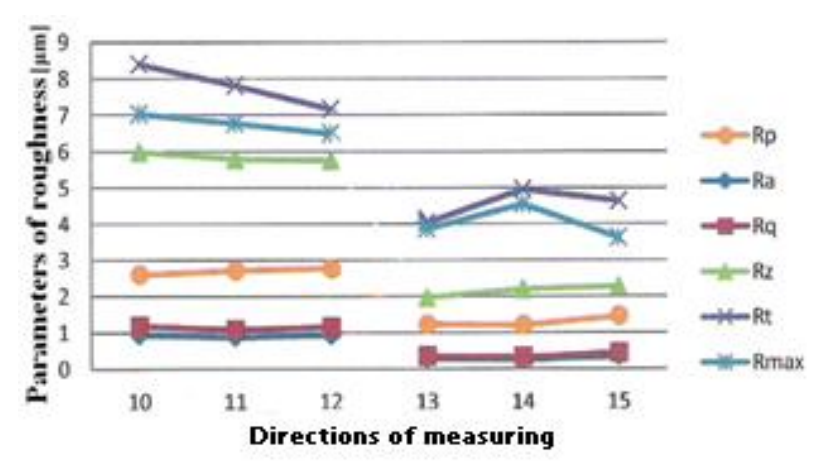

Fig. 19. Diagram of roughness parameters of the output lateral back surface of coated tool 13 unworn module $\mathrm{m}=3 \mathrm{~mm}$

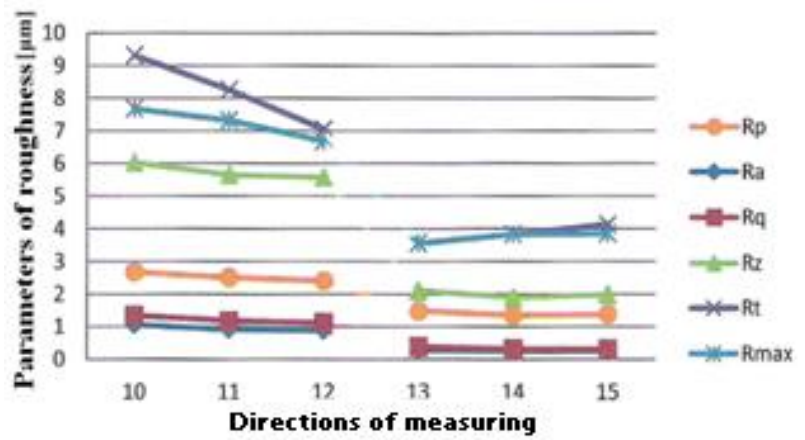

Fig. 20. Diagram of roughness parameters of the output lateral back surface of coated tool 13 worn-out module $\mathrm{m}=3 \mathrm{~mm}$

According to the results of the six most commonly used parameters of the roughness of the input lateral back surface of the model hob milling tools from the first part of the experimental research in which the roughness of the same tools were compared in the unworn and worn-out state, it can be concluded that the maximum values of the roughness parameters most often occur on the first direction of measurement in the case of worn-out tool, and the minimum values in the fifth direction of measurement in the case of unworn tool, which indicates that the worst change of the surface topography is in the worn-out zone near the cutting edge, with the note that the results of each parameter vary widely.

According to the results of the six most commonly used parameters of the roughness of the output lateral back surface of the model hob milling tools from the first part of the experimental research in which the roughness of the same tools were compared in the unworn and worn-out state, it can be concluded that the maximum values of the roughness parameters most often occur on the longitudinal tenth direction of measurement in the case of worn-out tool, and the minimum values in the transversal fourteenth direction of measurement in the case of unworn tool, which shows that the change of the topography of the output lateral back surface of the worn-out model tools is the greatest along the cutting edge, with the remark that the results of each parameter vary widely.

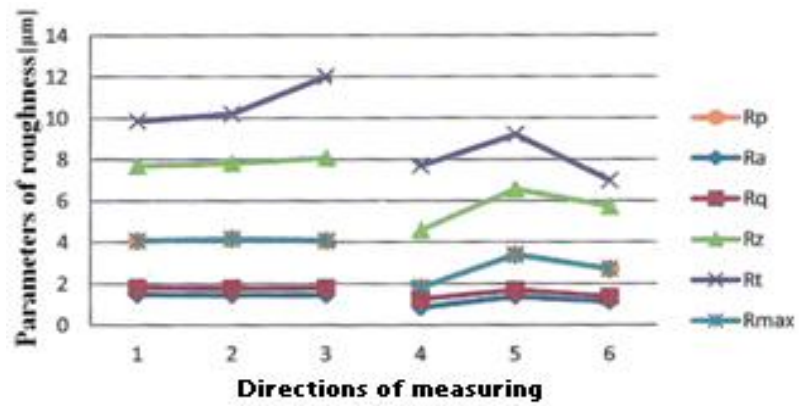

Fig. 21. Diagram of roughness parameters of the input lateral back surface of uncoated tool 22 worn-out module $\mathrm{m}=3 \mathrm{~mm}$

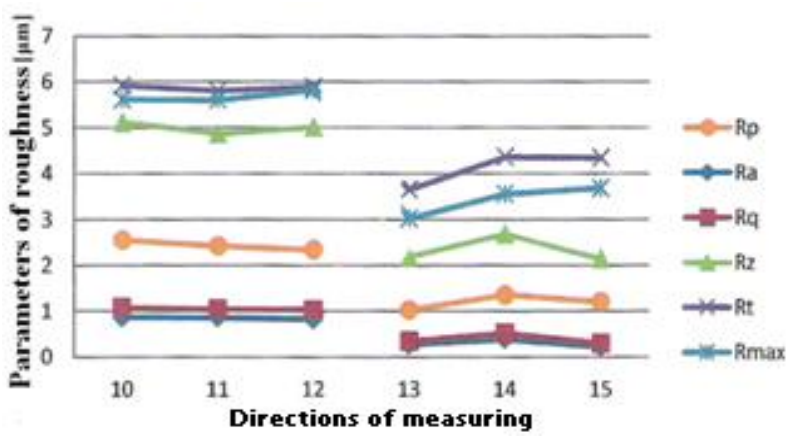

Fig. 22. Diagram of roughness parameters of the output lateral back surface of uncoated tool 22 worn-out module $\mathrm{m}=3 \mathrm{~mm}$

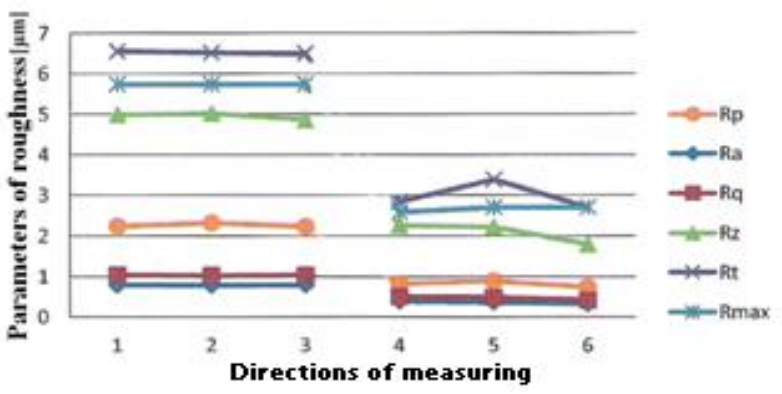

Fig. 23. Diagram of roughness parameters of the input lateral back surface of uncoated tool 55 worn-out module $\mathrm{m}=5 \mathrm{~mm}$

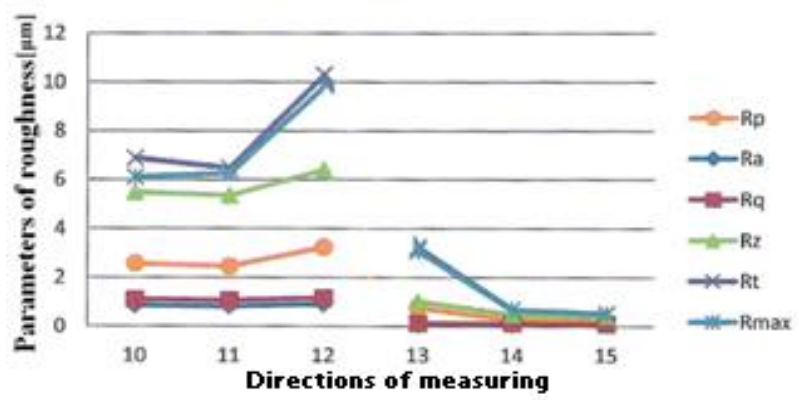

Fig. 24. Diagram of roughness parameters of the output lateral back surface of uncoated tool 55 worn-out module $\mathrm{m}=5 \mathrm{~mm}$ 


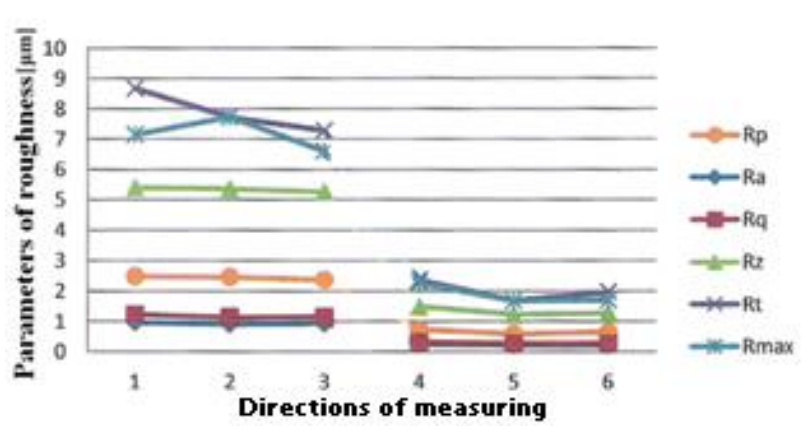

Fig. 25. Diagram of roughness parameters of the input lateral back surface of coated tool 73 worn-out module $\mathrm{m}=5 \mathrm{~mm}$

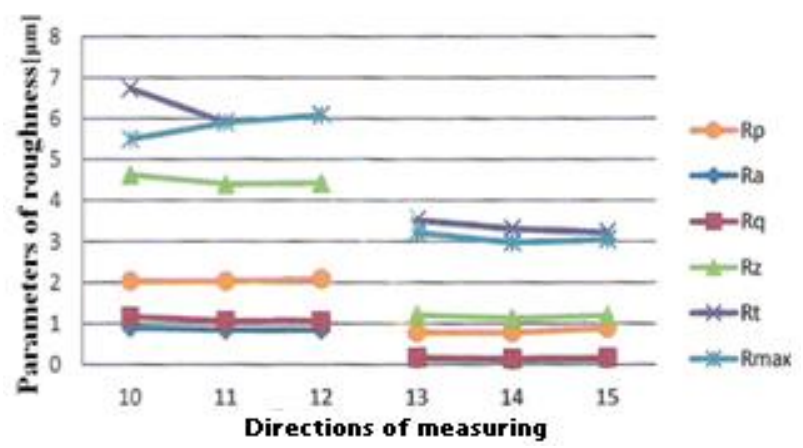

Fig. 26. Diagram of roughness parameters of the output lateral back surface of coated tool 73 worn-out module $\mathrm{m}=5 \mathrm{~mm}$

From the second part of the experiment, which included analyzes of the parameters of the roughness of the input lateral back surface of four groups of worn-out model hob milling tool, it can be concluded that the maximum values of the roughness parameters most often occur on the first three directions of measurement, because the tool of the module $m=5 \mathrm{~mm}$ has wider flank wear and minimum in the fifth and sixth direction of measurement in the groups in which the coated model tools were analyzed, while in the groups where the uncoated model tools were analyzed maximum roughness values were moved to the first and third direction of measurement, and the minimum values remained on the same measurement directions as coated, also with the remark that the results of each parameter vary widely.

From the second part of the experiment, which included analyzes of the parameters of the roughness of the output lateral back surface of four groups of thirteen worn-out modeled hob milling tools, it can be concluded that the maximum values of the roughness parameters are most commonly occurring on the longitudinal tenth direction of measurement, while in the case of uncoated tools maximum values of the parameters of the roughness displaced in the longitudinal eleventh and twelfth directions of measurement, which can be explained by the fact that the flank wear on the output lateral back surface are higher in the case of uncoated tools in the transversal fourteenth and fifteenth direction of measurement. It should also be noted here that the results of each parameter vary widely.

On the basis of the first and the second part of the experimental research it can be concluded that all the maximum values of roughness parameters at characteristic surfaces of the model hob milling tools are represented in longitudinal direction of measurement, while all minimum value of roughness parameters are represented in the crossdirection of measurement. Explanation arises from the fact that the measuring needle used for measurements in the directions of 1,2 and 3 , respectively and 10, 11 and 12 was moving in the direction of the normal to the grooves resulting from the final machining of the characteristic surface of model hob milling tools. The movement of the measuring needle was parallel with the aforementioned grooves for the directions 4, 5 and 6 , respectively and 13,14 and 15 .

\section{CONCLUSION}

The basic tribo-mechanical system during gear cutting by hob milling is made up of tribomechanical elements, work-piece, model hob milling tool and cutting fluid. The quality of the machined surface has a significant influence on the exploitation characteristics of tribo-mechanical elements.

Today, great efforts are being made to penetrate into the essence of the nature of the contact surface, and this is facilitated by new technologies and devices. The consequences of tribological processes are the changes that occur on the surface layer.

Research of the topography of the characteristic surfaces of the model hob milling tools have been performed on one of the most modern devices MahrSurf PS1 for testing the roughness parameters.

As can be seen from the results presented the roughness parameters $R_{a}$ and $R_{q}$ are parameters whose results are fairly uniform and their dissipation is insignificant. For the $R_{p}$ roughness parameter, the dissipation is slightly higher than the parameters $R_{a}$ and $R_{q}$, while the parameters of the roughness $R_{y}, R_{z}$ and $R_{\max }$ are the parameters in which the largest dissipation of the results is observed. 
Based on the results of measuring the six most commonly used roughness parameters $\left(R_{a}, R_{q}, R_{z}, R_{t}\right.$, $R_{\text {max }} R_{p}$ ) or the entire experimental research in this paper it can be concluded that the topography of unworn coated model hob milling tools is better than the topography of worn-out coated model hob milling tools noting that the results of each of the parameters vary differently.

The basic roughness parameters of the lateral back surfaces of the model hob milling tools cannot fully define the quality of this surface, so it would be necessary to use stochastic indicators of roughness for a more complex and better quality assessment of the profile of the tribo-mechanical element.

To complete the picture of the topography of the contact surfaces of the model hob milling tools, it is necessary in future investigations a precise definition of surface roughness through defining the distribution of the ordinates and the tops, the distribution of the inclination, the radius of the tops and recess of unevenness, carrying capacity curves of profile and others.

A two-dimensional analysis can often be used as a process monitoring that is limited in scope, but provides a simple indication, regardless of whether the topography changes. For a more complete understanding, a three-dimensional analysis of the topography of the characteristic surfaces of the model hob milling tools is necessary.

\section{REFERENCES}

[1] B. Sovilj, I. Sovilj-Nikić, D. Ješić, The effect of specific relationship between material and coating on tribological and protective features of the product. Metalurgija, 51 (1), 2012: 2124.

[2] I. Sovilj-Nikić, B. Sovilj, M. Kandeva, V. Gajić, S. Sovilj-Nikić, S. Legutko, P. Kovač, Tribological characteristics of hob milling tools from economic aspect. Journal of the Balkan Tribological Association, 18 (4), 2012: 577-585.

[3] M. Opalić, Prijenosnici snage i gibanja. Sveučilište u Zagrebu, FSB, Zagreb, 1998.

[4] B. Karpuschewski, H.J. Pieper, Innovations in Tool Development and Manufacturing. Proceedings of $13^{\text {th }}$ International Conference on Tools, 2012, Miskolc, Hungary, pp.21-26.

[5] K.-D. Bouzakis, G. Skoridatis, M. Michalidis, Innovative Methods for Characterizing
Coatings Mechanical Properties. Proceedings of International Conference "The Coatings 2008", October 2008, Kallithea, Greece

[6] I. Sovilj-Nikić, Modelovanje i optimizacija procesa odvalnog glodanja (Ph. D. Thesis). Fakultet tehničkih nauka, Novi Sad, (In Serbian - Unpublished)

[7] S. Veličković, S. Garić, B. Stojanović, A. Vencl, Tribological properties of alluminium matrix nanocomposites. Applied Engineering Letters, 1 (3), 2016: 72-79.

[8] A. Skulić, M. Bukvić, Tribological properties of piston-cylinder set in internal combustion engines. Applied Engineering Letters, 1 (1), 2016: 29-33.

[9] M. Kandeva-Ivanova, A. Vencl, D. Karastoyanov, Advanced Tribological Coatings for Heavy-Duty Applications: Case Studies. Prof. Marin Drinov Publishing House of Bulgarian Academy of Science, Sofia, 2016.

[10] M. Kandeva-Ivanova, D. Karastoyanov, B. Ivanova, E. Assenova, Tribological Interactions of Spheroidal Graphite Cast Iron Microalloyed by Tin. Prof. Marin Drinov Publishing House of Bulgarian Academy of Science, Sofia, 2016.

[11] A. Tudor, N. Sandu, I. Tounta, Tribologia contctului roata-sina. Editura Bren, Bucuresti, 2014.

[12] P. Panjan, M. Šekada, Zaščita orodij s trdimi PVD-prevlekami. Institut Jožef Stefan, Ljubljana, 2005. (In Slovenian)

[13] S. Tanasijević, Tribološki ispravno konstruisanje. Mašinski fakultet u Kragujevcu, Kragujevac, 2004. (In Serbian)

[14] B. Sovilj, Identifikacija triboloških procesa pri odvalnom glodanju (Ph. D. Thesis). Fakultet tehničkih nauka, Novi Sad, 1988. (In Serbian)

[15] L. Blunt, X. Jiang, Waviness and Primary Profile, Geometrical Product Specification. Warsaw University of Technology Printing House, Warsaw, 2001.

[16] J. Jozwik, K. Dziedzic, I. Usydus, P. Raos, HS 6-52 steel surface layer development in carboniteriding with zeroflow method. Technical Gazette, 23 (5), 2016: 1405-1409.

https://doi.org/10.17559/TV-20150402150811

[17] B. Križan, Osnove proračuna i oblikovanja konstrukcijskih elemenata. Školska knjiga, Zagreb, 2008. (In Serbian) 